\title{
Considering the Role of Neurodidactics in Medical Education as Inspired by Learning Studies and Music Education
}

\author{
Carlos Trenado $^{1} \cdot$ Nicole Pedroarena-Leal ${ }^{2} \cdot$ Diane Ruge $^{2}$ \\ Accepted: 20 November 2020 / Published online: 1 December 2020 \\ (C) International Association of Medical Science Educators 2020
}

\section{Introduction}

Students in medical school face challenges such as the huge amount of information they need to learn and emotionally challenging situations they are confronted with such as illness, suffering, and patient treatment dilemmas, which cause them feelings of uncertainty about possessing insufficient knowledge and skills [1].

During the last decades, an extensive body of research aimed at improving learning in medical settings, has been accumulated. In particular, numerous psychology and education reports have targeted strategies to improve retention of factual information, for instance, retrieval practice, linking ideas with concrete examples, concept maps, and use of audiovisual mnemonics [2, 3]. Other aspects addressed include the use of testing as an active element of learning which appears more effective than studying repeatedly, active methods of repetition such as free recall when trying to remember information learned, and retrieval of information at different time points for better retention of information [4]. Other authors stressed the importance of developing study techniques by taking into consideration the content intended to study and how it is learned. Particularly, these authors recommended studying in different locations; working in groups; defining simple outlines of a stick man to demonstrate various signs and symptoms of disease, a

Carlos Trenado and Nicole Pedroarena-Leal contributed equally to this work.

\footnotetext{
Carlos Trenado

carlos.trenadoc@gmail.com

$\triangle$ Diane Ruge

diane.ruge@gmail.com

1 Institute of Clinical Neuroscience and Medical Psychology, Medical Faculty, Heinrich Heine University, Moorenstr. 5, 40225 Duesseldorf, Germany

2 UCL-Institute of Neurology, University College London (UCL), Queen Square, London WC1N 3BG, UK
}

technique referred to as "stick men"; mind maps (as a revision technique); and flash cards and post-it-notes [5]. In addition, different types of learning for medical students have been identified, namely "deep style" dealing with understanding concepts with a strong interest in ideas; "strategic style" involving students' motivation to achieve the highest possible scores through good time management and study organization; and "surface apathetic style" putting emphasis on rote memorization and lack of understanding which is only intended to cope minimally with the course of study [6]. Moreover, several studies have been directed to determine factors that influence the choice of a particular learning style with the goal of improving the learning experience of medical students [7-10]. With respect to the learning environment, some reports have considered factors such as workload, sleep deprivation, clerical and administrative responsibilities, information management, available support, and the role of teachers and mentors [11].

Nevertheless, the relevant issue of whether the teaching environment (curriculum, learning techniques, teaching methods, learning technologies, etc.) needs to be adapted to the neurobiology of the individual brain has been discussed only by few authors [12]. In what follows, we revive this important debate as it may certainly impact assessment of learning and novel learning technologies in medical school. We base our discussion on representative studies targeting the neural mechanisms of learning and music education as prospective examples of the applicability of neurodidactics. Specifically, we discuss the role of neurodidactics or educational neuroscience in improving learning strategies for medical students. The debate whether neuroscience can contribute to the successes of education has been ongoing for decades. Undoubtedly, learning takes place in the brain and the effects of learning are mediated by the process of neural plasticity. These processes are shaped by internal and external characteristics that need to be integrated in current training of educators. This paper is a perspective or commentary; empirical work has to be supported in this field. 


\section{The Prospect of Neurodidactics in Learning Improvement}

Neurodidactics is based on the notion that learning is a dynamic process determined by the state of the developing brain, which can be potentially modified according to a specific need or learning goal [13-19]. Neurodidactics argues that strategies and methods used to organize teaching environments (curriculum, learning techniques, teaching methods, etc.) should be based on neurobiology principles, for instance, changes in the environment that supports modulation of brain plasticity associated with learning improvement $[20,21]$. Since there is a neurobiological basis for learning, it is reasonable to consider such knowledge in improving learning strategies and so adapt the medical curriculum to these conditions $[1,12]$. We highlight research studies that exemplify different ways in which neurodidactics could directly or indirectly support improvement of learning strategies.

\section{Improvement of Memory}

Previous studies have shown that monitoring brain activity during a study session is useful to predict how well people will remember information subsequently [22]. Functional magnetic resonance imaging (fMRI) studies focusing on improvement of long-term memory due to retrieval of information during a learning period have shown engagement of brain regions such as the anterior hippocampus, lateral temporal cortices, and the medial prefrontal cortex (PFC) [23].

Electroencephalographic (EEG) brain activity has been useful to assess the progression of learning in tasks such as typing. Particularly, it was observed that power changes in various EEG rhythms corresponded to different stages and difficulty levels of the learning process. Noteworthy, a decrease in beta and gamma power corresponded to features of binding and memory encoding [24].

Memory retrieval, which is often visualized as an on/ off process with a trigger or reminder to reactivate a past experience or specific information, has been shown to be concomitant with theta oscillations that have also been proposed as its neural signature [25].

Studies in aging populations support that resting network activity and connectivity patterns underlie enhancement of memory in older adults for meaningful associations [26]. It has also been shown that working memory (WM)-related brain activity is greater in older than in younger adults, while such cortical over-recruitment in advanced old age has been attributed to a compensatory mechanism [27]. Focusing on training-induced memory enhancement, it has been reported that younger adults show increased activity during memory encoding in occipito-parietal and frontal brain regions. In contrast, older adults did not show such an increase with the exception of those who did benefited from the training [28].

\section{Improvement of Attention}

By means of the relationship between EEG brain signals and attention levels during learning, some authors provided recovery methods to help students restore attention and so improve their learning efficacy. In particular, napping as a recovery method showed superior efficacy in comparison to playing mobile games or watching videos [29]. Interestingly, fMRI studies showed that behavioral reduction of distractor effects during a visual categorization task gives place to decreased responses at the middle frontal gyrus [30].

\section{Biomarkers of Learning}

fMRI studies performed on experienced physicians who learned to choose between two treatments in a series of virtual patient encounters revealed differential brain activation in the dorsolateral prefrontal cortex and the inferior parietal lobule between high and low performers. It was concluded that such differences could serve as a biomarker to identify efficient learners on novel decision tasks and in medical or other contexts [31]. fMRI studies addressing brain patterns of reading comprehension strategies, for instance, re-read, paraphrase, and self-explain, revealed activation in executive control and comprehension brain areas while learning from a text was associated with activation in the anterior prefrontal cortex (aPFC). It was speculated that a prospective role of the aPFC is facilitation of the integration of new knowledge from texts with prior knowledge [32].

Neurophysiological markers of learning are widely recognized. However, more recently, it has been possible to study more detailed mechanisms non-invasively in humans. Depotentiation (DP) is a crucial mechanism for the tuning of memory traces once LTP (long-term potentiation) has been induced via learning, artificial procedures, or other interventions. Thus, DP is an important process to consider when therapeutic interventions, such as psychotherapy, are administered. Noteworthy, recent transcranial magnetic stimulation (TMS) studies reported that the ratio LTP/DP might be a valuable marker for potential distortions of persistence versus deletion of memory traces represented by LTP-like plasticity [33].

Focusing on motor learning, the occurrence of changes in the cerebellum, the striatum, and motor cortices in the first stage has been reported, while further training leads to slower reorganization of the primary motor cortex (M1) [34]. Moreover, studies have shown that training of a motor sequence task results in increased activation of the M1 over 
different time periods [35]. In other words, different stages of motor learning might have different neurophysiological correlates.

\section{Learning in the Classroom}

Simultaneous EEG recording from students in the classroom enabled real-time inference of student engagement by means of attentional measures evoked by a video stimulus [36]. Recent studies also targeted assessment of reasoning in clinical students by analyzing the relationship between EEG features related to students' performance and gaze [37]. Likewise, some authors were able to estimate the level of student's visual attention in the classroom by monitoring EEG spectral changes [38]. EEG studies have also been directed to extract information about the effect of real versus virtual learning environments. While it was reported that more positive emotions were triggered in a real environment, the level of student engagement was approximately the same in both scenarios [39]. Moreover, a study monitoring brain activity of high school students over a period of 6 months revealed synchronization of brain oscillations when students were more engaged during class. Thus, brain-to-brain synchronization was assumed to reflect a sense of likeness and compatibility between teacher and students and between students [40].

\section{Neurodidactics in Music Education}

One example of the successful application of neurodidactics research is within the field of music education. In particular, EEG brain activation patterns during a melodic pitch discrimination task showed differences between musicians and non-musicians. Participants were divided into three groups: non-musicians, amateurs (defined as regularly playing or singing but without any formal training), and professional musicians with special training and knowledge in the analysis of harmonies and chords. A left-hemisphere dominance for the majority of professional musicians and right hemisphere lateralization for amateurs and non-musicians were reported. The differences in hemisphere dominance were attributed to differences in cognitive strategies between formally trained musicians and those without formal mental representations for the same information [41].

Musicians are a valuable "model" for effective learners who deliver in a very exact and precise manner. Formal training permits interval representation of music using covert speech, resulting in activation of the left frontal lobe whereas non-musicians are limited to a general understanding of the music, with no real representation annexed to the actual processing of what they hear [41]. Importantly, training with actual applied, directed, and practical curriculum (such as that received by amateurs) led to similar brain patterns as that visualized for professionally trained musicians, with bilateral lobe activation registered after training [41, 42]. Thus, it is suggested that teaching methods influence learning goals and information attained.

Notoriously, it has also been documented that neuroscientific models of music processing have been useful to define the concepts of curriculum design in the music school [43-45].

\section{Discussion}

The above-mentioned studies exemplify the prospect of neurodidactics not only in revealing brain developmental differences in relation to learning but also in defining brain biomarkers that could complement or outperform behavioral measures directed to assess the effectiveness of learning strategies. As already pointed out by some authors, such knowledge could be useful in supporting improvement of existing learning strategies to achieve maximal results, adapting an effective strategy in one domain for application in a different domain, and taking one or more complementary techniques and combining them into a more comprehensive learning strategy [46].

Due to that neurodidactics is based on research studies to accomplish its goals, some limitations need to be taken into account: (1) the majority of research studies are performed under laboratory conditions by using simple stimuli, while a real educational environment is complex and unpredictable; (2) meaningful results extracted from brain measures commonly require a high number of event-related responses or trials, which makes relevant to develop adaptive algorithms, internet platforms, and hardware that enable extraction of brain patterns in real-time continuous data; (3) simultaneous recording of brain and behavioral and physiological signals from different subjects in a realistic environment generates large amounts of data that would certainly be suitable for modern big data analytic approaches.

The use of technology in medical school for the facilitation of learning, improving motor skills, enhancing perceptual abilities, and practicing uncommon events has gained considerable popularity in recent years. In particular, podcasts, videos, mobile devices with apps, video games, simulators (virtual reality), and wearable devices are being considered relevant in addressing some of the learning challenges faced by medical students [47]. However, it has also been stressed that factors such as how to objectively measure their effectiveness and how its actual adoption changes students' learning habits and capabilities need to be taken into account [48]. In this respect, one of the key features of neurodidactics is the 
proposal of optimizing learning effectiveness in a personalized or customized fashion, e.g., by taking into consideration the fact that humans learn differently and present structural and functional brain differences.

A crucial skill in the study of medicine is timely retrieval of information. Due to that medical students are frequently confronted with emotional challenging situations, such retrieval of information has to be trained for scenarios of stress and sub-optimal wellbeing, which could certainly be addressed by applying neurodidactics approaches.

As medical students progress towards their studies, their focus switches from theoretical principles to clinical work and patient care. At this stage, not only rapid retrieval of specific information but also motor memory skills are required. Noteworthy, neuroscience studies have shown that motor memory is susceptible to be improved via learning strategies as exemplified by music learning. In the upcoming years, it is expected that neuroscience-based technologies boosting sensorimotor processing, motor memory, and alertness will be instrumental in optimizing physicians skills to perform specialized medical procedures with higher degree of expertise.

Among emerging approaches for learning improvement is the so-called neurofeedback, which uses real-time monitoring of brain oscillatory activity to regulate brain states [49]. In light of the principles of neural plasticity, repeated sessions of neurofeedback have the potential to normalize brain activity patterns with a corresponding learning effect [50]. It is expected that such learning approach will be able to inform the educational needs of medical students.

The applicability of fMRI for education and learning purposes is expected to increase in the upcoming years as a result of the awareness of different areas of opportunity and efforts to resolve current technical issues, for instance, by using multimodal neuroimaging approaches in combination with novel approaches to estimate causal relationships between brain activity and behavioral learning associations [51].

Notwithstanding all recent advances in neuroscience and neurotechnology, we stress that the real applicability of neurodidactics in medical education will only be plausible with the openness and committed participation of medical educators, practitioners, and students working together with scientists from other disciplines to consolidate an evidencebased science of learning that targets the needs of (medical) students.

The marriage of neuroscience knowledge and education has long been avoided. Educators and teachers often derive from "cultural schools" and seem to resist the fundamental idea that learning is a brain-based process in which the knowledge of how the brain processes is useful and indeed crucial for students' success. On the other hand, neuroscientists are often not trained as teachers or educators. The mentioned research studies demonstrate a rather direct approach, i.e., neuroscientific testing in relation to an education-relevant question (retrieval, memory, attention, etc.). Certain settings relevant to education are matched with neurotechnology methods and correlations can be made. However, recent studies show important effects of giving teachers or educators neuroscience knowledge relevant to teaching and learning and thereby indirectly improving the success and wellbeing of students and teachers: "Findings suggest how neuroscience holds the potential to support teachers development of theoretical coherence in their understanding of learning and pedagogy" [52]. The effects of teaching students' wellbeing, based on a combination of neuroscience-based facts, have been suggested to enhance cognitive and learning benefit in a recent study [53]. Without any doubt, neuroscience knowledge can improve learning and education. Unfortunately, over a long time, the intersection between neuroscience and education has not been nurtured [54]. However, the examples and literature demonstrate that the use of neuroscience for (medical) education has been and can be further developed at different levels, i.e., direct application by modification of brain function and indirect application by insight improvement. The need for empirical studies cannot be over emphasized.

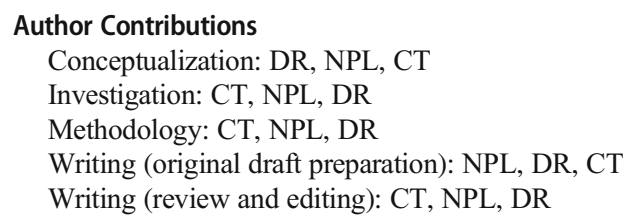

Funding The Dorothy Feiss Scientific Research Grant.

\section{Compliance with Ethical Standards}

Competing Interests The authors declare that they have no competing interests.

Ethical Approval NA

Informed Consent NA

\section{References}

1. Weurlander M, Lönn A, Seeberger A, Hult H, Thornberg R, Wernerson A. Emotional challenges of medical students generate feelings of uncertainty. Med Educ. 2019;53:1037-48. https://doi. org/10.1111/medu.13934.

2. Richmond A, Cranfield T, Cooper N. Study tips for medical students. BMJ. 2019;365:k663.

3. Yang A, Goel H, Bryan M, Robertson R, Lim J, Islam S, et al. The Picmonic $®$ Learning System: enhancing memory retention of medical sciences, using an audiovisual mnemonic Web-based learning platform. Adv Med Educ Pract. 2014;5:125-32. https://doi.org/10. 2147/AMEP.S61875.

4. Augustin M. How to learn effectively in medical school: test yourself, learn actively, and repeat in intervals. Yale $J$ Biol Med. 2014;87(2):207-12. 
5. Fowler A, Whitehurst K, Al Omran Y, Rajmohan S, Udeaja Y, Koshy K, et al. How to study effectively. Int J Surg Oncol. 2017;2(6):e31. https://doi.org/10.1097/IJ9.0000000000000031.

6. Leite WL, Svinicki M, Shi Y. Attempted validation of the scores of the VARK: learning styles inventory with multitrait-multimethod confirmatory factor analysis models. Educ Psychol Meas. 2010;70: 323-39.

7. Chonkar SP, Ha TC, Chu SSH, Ng AX, Lim MLS, Ee TX, et al. The predominant learning approaches of medical students. BMC Med Educ. 2018;18:17. https://doi.org/10.1186/s12909-018-1122-5.

8. Subasinghe SD, Wanniachchi DN. Approach to learning and the academic performance of a group of medical students-any correlation. Stud Med J. 2009;3:5-10.

9. Shankar PR, Balasubramanium R, Dwivedi NR. Approach to learning of medical students in a Caribbean medical school. Educ Med J. 2014;6:e33-40.

10. Reid WA, Evans P, Duvall E. Medical students' approaches to learning over a full degree programme. Med Educ Online. 2012;17:1-7.

11. Lacasse M, Théorêt J, Skalenda P, Lee S. Challenging learning situations in medical education: innovative and structured tools for assessment, educational diagnosis, and intervention. Part 1: history or data gathering. Can Fam Physician. 2012;58(4):481-4.

12. Friedlander MJ, Andrews L, Armstrong EG, Aschenbrenner C, Kass JS, Ogden P, et al. What Can Medical Education Learn From the Neurobiology of Learning? Acad Med. 2011;86(4):415-20. https:// doi.org/10.1097/acm.0b013e31820dc197.

13. Thomas MSC, Ansari D, Knowland VCP. Annual Research Review: Educational neuroscience: progress and prospects. $J$ Child Psychol Psychiatry. 2019;60:477-92. https://doi.org/10. 1111/jcpp.12973.

14. Feiler JB, Stabio ME. Three pillars of educational neuroscience from three decades of literature. Trends Neurosc Educ. 2018;13: $17-25$.

15. Serrano MC, Losada JM, Martín JS, Polo FZ. Neuro-Didactics and Social Sciences: An Experience of the Application of DAS Sequence in the Geography Classroom. Proceedings. 2018;2:1325.

16. Tandon PN, Singh NC. Educational Neuroscience: Challenges and Opportunities. Ann Neurosci. 2016;23(2):63-5. https://doi.org/10. $1159 / 000443560$.

17. Anastasia C. The Social Framework of Learning via Neurodidactics. Creative Educ. 2016;7:2175-92. https://doi.org/ 10.4236/ce.2016.715215

18. Gabrieli JDE. The promise of educational neuroscience: Comment on Bowers (2016). Psychol Rev. 2016;123(5):613-9.

19. Lee HW, Juan CH. What can cognitive neuroscience do to enhance our understanding of education and learning? J Neurosci Neuroeng. 2013;2(4):393-9. https://doi.org/10.1166/jnsne.2013.1064.

20. Coch D, Ansari D. Thinking about mechanisms is crucial to connecting neuroscience and education. Cortex. 2008;45:546-7. https://doi.org/10.1016/j.cortex.2008.06.001.

21. Meltzoff AN, Kuhl PK, Movellan J, Sejnowski TJ. Foundations for a New Science of Learning. Science. 2009;325(5938):284-8.

22. Sandia National Laboratories (2012). Monitoring brain activity during study can help predict test performance. ScienceDaily. Retrieved February 1, 2020 from www.sciencedaily.com/releases/ 2012/09/120919103144.htm.

23. Wing EA, Marsh EJ, Cabeza R. Neural correlates of retrieval-based memory enhancement: An fMRI study of the testing effect. Neuropsychologia. 2013;51:2360-70.

24. Gutiérrez D, Ramírez-Moreno MA. Assessing a learning process with functional ANOVA estimators of EEG power spectral densities. Cogn Neurodyn. 2016;10(2):175-83. https://doi.org/10.1007/ s11571-015-9368-7.

25. Gruhn, W. (2004). Neurodidactics - a New Scientific Trend in Music Education? Retrieved from https://www.semanticscholar.
org/paper/Neurodidactics---a-New-Scientific-Trend-in-Music-\% 3F-Gruhn/e711c17d8a1f2ae6717216aa844dfe21218586bc.

26. Amer T, Giovanello KS, Nichol DR, Hasher L, Grady CL. Neural Correlates of Enhanced Memory for Meaningful Associations with Age. Cereb Cortex. 2019;29(11):4568-79. https://doi.org/10.1093/ cercor/bhy334.

27. Suzuki M, Kawagoe T, Nishiguchi S, Abe N, Otsuka Y, Nakai R, et al. Neural Correlates of Working Memory Maintenance in Advanced Aging: Evidence From fMRI. Front Aging Neurosci. 2018;10:358. https://doi.org/10.3389/fnagi.2018.00358.

28. Nyberg L, Sandblom J, Jones S, Stigsdotter Neely A, Magnus Petersson K, Ingvar M, et al. Neural correlates of training-related memory improvement in adulthood and aging. PNAS. 2003;100(23):13728-33. https://doi.org/10.1073/pnas.1735487100.

29. Chiang H, Hsiao K, Liu L. EEG-Based Detection Model for Evaluating and Improving Learning Attention. J Med Biol Eng. 2018;38:847-56. https://doi.org/10.1007/s40846-017-0344-z.

30. Kelley TA, Yantis S. Neural correlates of learning to attend. Front Hum Neurosci. 2010;4:216. https://doi.org/10.3389/fnhum.2010. 00216.

31. Downar J, Bhatt M, Montague PR. Neural Correlates of Effective Learning in Experienced Medical Decision-Makers. PLoS ONE. 2011;6(11):e27768. https://doi.org/10.1371/journal.pone.0027768.

32. Moss J, Schunn CD, Schneider W, McNamara DS, VanLehn K. An fMRI study of strategic reading comprehension: Cognitive control and discourse comprehension. Neuroimage. 2011;58:675-86.

33. Pedroarena-Leal N, Heidemeyer L, Trenado C, Ruge D. Human Depotentiation following Induction of Spike Timing Dependent Plasticity. Biomedicines. 2018;6:71.

34. Unsworth N, Fukuda K, Awh E, Vogel EK. Working memory and fluid intelligence: Capacity, attention control, and secondary memory retrieval. Cogn Psychol. 2014;71:1-26. https://doi.org/10.1016/ j.cogpsych.2014.01.003.

35. Ericsson KA, Kintsch W. Long-term working memory. Psychol Rev. 1995;102(2):211-45.

36. Poulsen AT, Kamronn S, Dmochowski J, Parra LC, Hansen LK. EEG in the classroom: Synchronised neural recordings during video presentation. Sci Rep. 2017;7:43916. https://doi.org/10.1038/ srep43916.

37. Jraidi I, Khedher A, Chaouachi M, Frasson C. Assessing Students' Clinical Reasoning Using Gaze and EEG Features. ITS. 2019:4756.

38. Ko L-W, Komarov O, Hairston WD, Jung T-P, Lin C-T. Sustained Attention in Real Classroom Settings: An EEG Study. Front Hum Neurosci. 2017;11:388. https://doi.org/10.3389/fnhum.2017. 00388.

39. Alwedaie SA, Khabbaz HA, Hadi SR, Al-Hakim R. EEG-Based Analysis for Learning through Virtual Reality Environment. $J$ Biosens Bioelectron. 2018;9:249. https://doi.org/10.4172/21556210.1000249.

40. Dikker S, Wan L, Davidesco I, Kaggen L, Oostrik M, McClintock $\mathrm{J}$, et al. Brain-to-brain synchrony tracks real-world dynamic group interactions in the classroom. Curr Biol. 2017;27:1375-80. https:// doi.org/10.1016/j.cub.2017.04.00.

41. Altenmüller E, Gruhn W, Parlitz D, Liebert G. The impact of music education on brain networks: Evidence from EEG-studies. Int $J$ Music Educ. 2000;35(1):47-53. https://doi.org/10.1177/ 025576140003500115.

42. Altenmüller E. Cortical DC-potentials as electrophysiological correlates of hemispheric dominance of higher cognitive functions. Int J Neurosci. 1989;47(1-2):1-14.

43. Koelsch S, Siebel WA. Towards a neural basis of music perception. Trends Cogn Sci. 2005;9(12):578-84.

44. Koelsch S. Toward a neural basis of music perception - a review and updated model. Front Psychol. 2011;2:1-20. 
45. Collins A. Neuroscience meets music education: Exploring the implications of neural processing models on music education practice. Int J Music Educ. 2013;31(2):217-31. https://doi.org/10.1177/ 0255761413483081.

46. Colvin R. Optimising, generalising and integrating educational practice using neuroscience. NPJ Sci Learn. 2016;1:16012. https://doi.org/10.1038/npjscilearn.2016.12.

47. Guze, P. Using Technology to Meet the Challenges of Medical Education. Trans Am Clin Climatol Assoc. 2015, 126. 260-270.

48. Gupta, J. (2017). Harnessing the power of technology in medical education [OUP blog]. Retrieved January 31, 2020, from https:// blog.oup.com/2017/12/technology-in-medical-education/.

49. Sitaram R, Ros T, Stoeckel L, Haller S, Scharnowski F, LewisPeacock J, et al. Closed-loop brain training: the science of neurofeedback. Nat Rev Neurosci. 2017;18:86-100.

50. Enriquez-Geppert S, Huster RJ, Herrmann CS. EEGNeurofeedback as a Tool to Modulate Cognition and Behavior: A Review Tutorial. Front Hum Neurosci. 2017;11:51. https://doi. org/10.3389/fnhum.2017.00051.
51. Seghier ML, Fahim MA, Habak C. Educational fMRI: From the Lab to the Classroom. Front Psychol. 2019;10:2769. https://doi. org/10.3389/fpsyg.2019.0S2769.

52. Michelle Tan YS, Johnston Amiel J. Teachers learning to apply neuroscience to classroom instruction: case of professional development in British Columbia. Prof Dev Educ. 2019:1-18. https:// doi.org/10.1080/19415257.2019.1689522.

53. Hawthorne BS, Vella-Brodrick DA, Hattie J. Well-Being as a Cognitive Load Reducing Agent: A Review of the Literature. Front Educ. 2019;4:121. https://doi.org/10.3389/feduc.2019. 00121.

54. Atherton, M., University of Minnesota. Applying the neurosciences to education research. Can cognitive neuroscience bridge the gap? Part 1. Retrieved from: https://citeseerx.ist.psu.edu/viewdoc/ download?doi=10.1.1.78.4727\&rep=rep1\&type=pdf.

Publisher's Note Springer Nature remains neutral with regard to jurisdictional claims in published maps and institutional affiliations. 